\title{
Destaques da ASCO 2016
}

\section{Imunoterapia no Tratamento \\ do Cancro do Pulmão}

\section{Rastreio do Cancro do Pulmão: Considerações Lógicas e Práticas}

Highlights of ASCO 2016

Immunotherapy in Lung Cancer Treatment

Lung Cancer Screening: Rationale and Practical Considerations

Bárbara Parente ${ }^{1}$

\section{RESUMO}

1. Inibidores de immune checkpoint são uma promessa na luta contra o cancro do pulmão e outros tumores malignos, alterando o microambiente do tumor e bloqueando a evasão ao sistema imunitário. Dois anticorpos anti-PD-1, nivolumab e pembrolizumab, estão aprovados para uso clínico, no cancro do pulmão, doença avançada em segunda linha. Anticorpos PD-L1 tal como atezolizumab e MEDI-4736 estão em desenvolvimento clínico e são alvo atual de vários estudos de fase II/III inclusivamente a decorrer em Portugal; tratamento de segunda linha em doentes com cancro do pulmão de não pequenas células doença avançada tem tido até agora como opção padrão o docetaxel.

2. Desde a publicação dos resultados do National Lung Screening Trial (NLST) em 2011, o rastreio do cancro do pulmão com tomografia computorizada de dose baixa tem sido o centro da investigação, guidelines e discussão geral deste tema. O racional para o screening tem evoluído nos últimos anos, dado que hospitais e outros sistemas de saúde ganharam experiência na implementação de programas de rastreio. O screening também mostra a importância do tabagismo, não apenas como um fator de risco para o cancro, mas também como uma variável que pode afetar drasticamente os resultados do cancro.

Estas foram, entre outras, questões discutidas por Especialistas no 2016 ASCO Annual Meeting - American Society of Clinical Oncology, que decorreu em Chicago de 3 a 7 de junho de 2016.

PALAVRAS-CHAVE: Carcinoma Pulmonar de Células Não Pequenas/quimioterapia; Carcinoma Pulmonar de CéluIas Não Pequenas/imunologia; Imunoterapia; Inibidores de Immune Checkpoint 


\section{ABSTRACT}

1. Immune checkpoint inhibitors show promise in combating lung cancer and other malignancies by altering the tumor microenvironment and blocking the immune system evasion that allows cancers to grow and proliferate. Two anti-PD-1 antibodies, nivolumab and pembrolizumab, are now in clinical use. PD-L1 antibodies such as atezolizumab and MEDI-4736 are in clinical development. Second-line treatment in patients with advanced non-small-cell lung cancer has traditionally involved switching the chemotherapeutic agent, with docetaxel as one standard option.

2. Since the publication of the National Lung Screening Trial's (NLST) results in 2011, low-dose computed tomography screening has been the focus of substantial research, guidelines, and general discussion. The rationale for screening has evolved in the intervening years, and hospitals and health systems have gained experience in implementing screening programs. Research has also begun to show how important smoking is, not just as a risk factor for cancer, but as a variable that can dramatically affect cancer outcomes. Experts discussed these issues during 2016 ASCO Annual Meeting - American Society of Clinical Oncology, June 3 a 7, Chicago, 2016

KEYWORDS: Carcinoma, Non-Small-Cell Lung/drug therapy; Carcinoma, Non-Small-Cell Lung/immunology; Immune checkpoint inhibitors; Immunotherapy

\section{IMUNOTERAPIA NO TRATAMENTO DO CANCRO DE PULMÃO IMMUNOTHERAPY IN LUNG CANCER TREATMENT}

Gregory A. Masters e Dhaval Shah, começam por comentar que numa recente pesquisa online de "cancro, imunoterapia e pulmão", esta produziu 1.280.000 resultados, sem dúvida o reflexo da explosão da imunoterapia no tratamento desta doença. Recentemente, os inibidores de checkpoint imunes têm sido desenvolvidos e mostraram ser uma promessa no combate ao cancro do pulmão e outros tumores malignos, alterando o microambiente tumoral e bloqueando a evasão ao sistema imunitário, evitando o crescimento e desenvolvimento neoplásicos.

\section{O PAPEL DA IMUNOTERAPIA}

Com base na necessidade de opções de tratamento mais eficazes para o cancro do pulmão de não pequenas células (CPNPC) resistente à quimioterapia (QT), desenvolveram-se ensaios clínicos para avaliar a eficácia de inibidores de PD-1 e PD-L1 no cancro de pulmão, fármacos inibidores de checkpoint com comprovada eficácia no tratamento do melanoma.

Dois ensaios de fase III confirmaram o benefício de nivolumab em tratamento de segunda linha nos doentes com CPNPC doença avançada. No estudo Cheque Mate 017 com docetaxel, 272 pacientes com CPNPC de tipo escamoso obtiveram uma sobrevida global mediana de 9,2 meses com nivolumab versus 6,0 meses com docetaxel e uma sobrevida média ao $1^{\circ}$ ano de $42 \%$ com nivolumab versus $24 \%$ com docetaxel. Da mesma forma, no estu- do Cheque Mate 057, nivolumab versus docetaxel em doentes com CPNPC não escamosos evidenciou uma sobrevida global de 12,2 meses em doentes tratados com nivolumab versus 9,4 meses em doentes tratados com docetaxel, e uma sobrevida ao $1^{\circ}$ ano de $51 \%$ com nivolumab contra 39\% com docetaxel. A análise de subgrupo deste último estudo mostrou maior eficácia para todos os doentes com tumores PD-L1-positivos.

O ensaio KEYNOTE-010 avaliou o papel de pembrolizumab (outro anticorpo anti-PD-1) em doentes previamente tratados com CPNPC doença avançada em que pelo menos $1 \%$ das células do tumor tinham expressão de DP-L1. Um total de 1.034 pacientes receberam pembrolizumab ( $2 \mathrm{mg} / \mathrm{kg}$ ou $10 \mathrm{mg} / \mathrm{kg}$ ) ou docetaxel ( $75 \mathrm{mg} / \mathrm{mg}$ ) em cada 3 semanas. No braço de pembrolizumab, a sobrevida global mediana foi de 10,4 meses na dose de 2 mg/kg e 12,7 meses na dose de $10 \mathrm{mg} / \mathrm{kg}$ e no braço do docetaxel foi de 8,5 meses. Assim, a sobrevida global foi superior com ambas as doses de pembrolizumab comparativamente ao docetaxel. Em doentes com expressão PD-L1 em pelo menos 50\% de células do tumor a sobrevida global foi de 14,9 meses com pembrolizumab na dose de $2 \mathrm{mg} / \mathrm{kg}$ e 17,3 meses com pembrolizumab $10 \mathrm{mg} / \mathrm{kg}$ versus 8,2 meses com docetaxel.

Com base nestes ensaios, o FDA aprovou o nivolumab e o pembrolizumab em monoterapia para tratamento de segunda linha de doentes com CPNPC doença avançada. Atualmente, para o uso de nivolumab não é necessário avaliar a expressão PD-L1. O pembrolizumab está presentemente aprovado para doentes com expressão de PD-L1 > 50\%.

A toxicidade de ambos os anticorpos inclui efeitos adversos imuno-relacionados de grau III em cerca de 10- 
14\% dos doentes. Os efeitos laterais mais comuns com anticorpos PD-1 são as erupções cutâneas e o prurido. A diarreia de grau 3/4 ou colite é observada em cerca de $1 \%$ e a pneumonite grau $3 / 4$ em cerca de $2 \%$ dos doentes. Efeitos secundários imuno-mediados menos comuns incluem as alterações da função hepática e renal, hipotiroidismo, entre outros. É importante o estabelecimento de protocolos de cooperação com especialidades afins aos efeitos laterais, nomeadamente endocrinologia, no sentido de obter um maior controlo dos efeitos adversos e aumento da qualidade de vida.

O papel de outros anticorpos PD-L1, como o atezolizumab e durvalumab, está agora sob investigação em doentes com CPNPC doença avançada. Os estudos estão a avaliar o papel dos anticorpos PD-1 ou PD-L1, em combinação com quimioterapia em primeira e segunda linha, no CPNPC doença avançada. Decorrem, também, estudos que investigam o papel de dupla inibição de checkpoints imunes com a adição de anticorpos CTLA-4 e inibidores de PD-L1 e PD-1.

Existem, ainda, estudos em curso que investigam o papel dos inibidores checkpoint imunológicos em fases mais precoces do CPNPC, como adjuvante pós-cirurgia ou em terapêutica combinada com radioterapia ou quimio-radioterapia em estádios III de doença.

\section{RASTREIO DO CANCRO}

\section{DO PULMÃO: CONSIDERAÇÕES PRÁTICAS E RACIONAIS LUNG CANCER SCREENING: RATIONALE AND PRACTICAL CONSIDERATIONS}

"A maioria das evidências que levaram à aprovação do rastreio vem da avaliação do National Lung Screening Trial", disse Denise Aberle e David Geffen da School of Medicine na University of California, Los Angeles (UCLA), que presidiu a esta sessão educacional. Foi até hoje o único estudo que mostrou benefício da mortalidade e "é certamente o maior estudo até hoje de rastreio dedicado ao cancro do pulmão. O National Lung Screening Trial (NLST) incluiu 53.454 fumadores com carga tabágica elevada, com idades entre os 55 e 74 anos, selecionados aleatoriamente para realização de tomografia computorizada (TC) de baixa dose ou radiografia de tórax uma vez por ano durante 3 anos. Após um acompanhamento de 6,5 anos, houve uma redução da mortalidade relativa por cancro do pulmão de $20 \%$ e uma redução de mortalidade de todas as causas em 6,7\%. $\bigcirc$ número de indivíduos necessários para evitar uma morte foi de 320, um número que se compara favoravelmente a outros rastreios, como a mamografia.
Ainda assim, alguns dos detalhes de rastreio permanecem em debate. A idade e o tabagismo não são por si só suficientes na seleção dos candidatos e torna-se necessário encontrar outras formas de identificar a população em risco.

O National Comprehensive Cancer Network (NCCN) desenvolveu dois tipos de critérios de elegibilidade, um com base nos critérios do NLST e outro que incluiu indivíduos com idade de 50 ou mais anos e baixando a carga tabágica de 30 para 20 unidades maço ano. Outra forma para reduzir os falso-positivos prende-se com a dimensão do nódulo pulmonar avaliado. No NLST os nódulos entre 4 e 6 mm representavam 51,0\% de todos os casos correspondendo apenas a 1\% dos tumores. Assim, o limite mínimo pode ser aumentado sem pôr em causa a fiabilidade do rastreio por TC.

Abbie Begnaud, da Universidade de Minnesota, referiu que desde a implementação dos programas de rastreio "tem sido uma constante avalanche de regulamentos, diretrizes, complicações e atualizações". Existe, presentemente, uma grande variedade de normas e recomendações de sociedades profissionais, incluindo ASCO, o American College of Chest Physicians, a American Cancer Society, e outros. Embora estas entidades difiram em alguns detalhes há linhas comuns a seguir na implementação de um programa. Os componentes básicos de elegibilidade de idade e tabagismo são consistentes, assim como as orientações sobre técnicas de imagem e interpretação. Muitas orientações também incluem recomendações sobre a cessação do tabagismo, abordagens no contexto de equipa multidisciplinar e supervisão do programa de triagem. A cessação tabágica possui um efeito importante sobre a mortalidade por cancro do pulmão e um estudo recente refere que a evicção do consumo de tabaco é tão eficaz como o rastreio por TC de baixa dose de radiação.

Existe uma grande lacuna na pesquisa dos efeitos do consumo de tabaco e resposta ao tratamento no cancro do pulmão. No entanto, e a título de exemplo, algumas pesquisas mostraram uma redução acentuada da eficácia da radioterapia em fumadores.

Por último, foi referido que face ao elevado custo dos fármacos, a abordagem relativa do tabaco pode constituir um método extremamente valioso para melhorar os resultados terapêuticos no cancro do pulmão.

CONFLITOS DE INTERESSE: Os autores declaram a inexistência de conflitos de interesse na realização do trabalho.

FONTES DE FINANCIAMENTO: Não existiram fontes externas de financiamento para a realização deste artigo. 